\title{
Conflicts of interest and critiques of the use of systematic reviews in policymaking: an analysis of opinion articles
}

\author{
Susan R Forsyth', Donna H Odierna ${ }^{2}$, David Krauth ${ }^{2}$ and Lisa A Bero $2,3,4^{*}$
}

\begin{abstract}
Background: Strong opinions for or against the use of systematic reviews to inform policymaking have been published in the medical literature. The purpose of this paper was to examine whether funding sources and author financial conflicts of interest were associated with whether an opinion article was supportive or critical of the use of systematic reviews for policymaking. We examined the nature of the arguments within each article, the types of disclosures present, and whether these articles are being cited in the academic literature.
\end{abstract}

Methods: We searched for articles that expressed opinions about the use of systematic reviews for policymaking. We included articles that presented opinions about the use of systematic reviews for policymaking and categorized each article as supportive or critical of such use. We extracted all arguments regarding the use of systematic reviews from each article and inductively coded each as internal or external validity argument, categorized disclosed funding sources, conflicts of interest, and article types, and systematically searched for undisclosed financial ties. We counted the number of times each article has been cited in the "Web of Science." We report descriptive statistics.

Results: Articles that were critical of the use of systematic reviews $(n=25)$ for policymaking had disclosed or undisclosed industry ties 2.3 times more often than articles that were supportive of the use $(n=34)$. We found that editorials, comments, letters, and perspectives lacked published disclosures nearly twice as often (60\% v. 33\%) as other types of articles. We also found that editorials, comments, letters, and perspectives were less frequently cited in the academic literature than other article types (median number of citations $=5 \mathrm{v} .19$ ).

Conclusions: It is important to consider whether an article has industry ties when evaluating the strength of the argument for or against the use of systematic reviews for policymaking. We found that journal conflict of interest disclosures are often inadequate, particularly for editorials, comments, letters, and perspectives and that these articles are being cited as evidence in the academic literature. Our results further suggest the need for more consistent and complete disclosure for all article types.

Keywords: Systematic reviews, Health policy, Conflicts of interest, Bias

\footnotetext{
* Correspondence: lisa.bero@sydney.edu.au

${ }^{2}$ Department of Clinical Pharmacy, University of California, San Francisco, CA, USA

${ }^{3}$ Institute for Health Policy Studies, University of California, San Francisco, CA, USA

Full list of author information is available at the end of the article
}

\section{Biomed Central}

(c) 2014 Forsyth et al.; licensee BioMed Central Ltd. This is an Open Access article distributed under the terms of the Creative Commons Attribution License (http://creativecommons.org/licenses/by/4.0), which permits unrestricted use, distribution, and reproduction in any medium, provided the original work is properly credited. The Creative Commons Public Domain Dedication waiver (http://creativecommons.org/publicdomain/zero/1.0/) applies to the data made available in this article, unless otherwise stated. 


\section{Background}

Systematic reviews are often used to inform practice guidelines and public and private sector health policy decisions and are often used as an alternative to expert opinion or consensus conferences [1-4]. For example, systematic reviews have been used to guide policymaking around such issues as tobacco control and to set blood alcohol levels at which drivers are considered intoxicated [2]. States have used systematic reviews to evaluate whether policies for managing prison populations are working and cost effective [2]. Such use is not without controversy. While some authors argue that systematic reviews are the highest form of evidence and provide a solid basis for policymaking [1,2], others argue that these studies are methodologically flawed or limited in scope [5]. Editorials, letters, and other opinion pieces are important because they can inform debate about controversial topics. Furthermore, these articles are sometimes cited as if they are original research; a letter in the New England Journal of Medicine critical of a systematic review on secondhand smoke [5] has been cited 30 times as evidence of the flaws of systematic reviews, according to the Web of Science.

Systematic reviews synthesize the results of primary qualitative and quantitative research, using strategies to reduce bias [6,7]. Systematic reviews of qualitative research summarize and narratively synthesize results using a range of methods [8-10]. Meta-analyses are systematic reviews that summarize results quantitatively. This technique enables researchers to combine the results of several studies into a single effect estimate [11]. We use the term "systematic review" to refer to both systematic reviews and meta-analyses. Depending on the rigor of the proto$\mathrm{col}$, the quality of the results of systematic reviews can be quite variable. High-quality reviews are characterized by a pre-defined protocol, clearly stated research questions, pre-defined eligibility criteria for studies, reproducible methodology, comprehensive search strategies to identify all studies and unpublished research that meet eligibility criteria, quality assessments including assessment of risk of bias, and systematic syntheses and presentation of findings [11]. Previous research has demonstrated that study results and conclusions may be influenced by funding sources and author conflicts of interest (COI) [12]. Primary studies or reviews funded by the pharmaceutical or tobacco industries are more likely to having findings or conclusions that favor the sponsor's product than those funded by non-industry sources [12-14].

However, little research has been done on whether industry ties influence the conclusions of articles that contain opinions on the use of systematic reviews for health policy decisions. Therefore, we examined financial and other COI disclosed by authors of articles with opinions about the use of systematic reviews in policymaking. We investigated whether affiliations, funding sources, financial ties, and other COI of authors were associated with support or criticism of the use of systematic reviews. Further, we qualitatively summarized the types of arguments presented.

Despite the importance of knowing a study's funding source and authors' COI, it is often difficult to find complete information. Disclosure policies vary among journals and may be different for research articles and opinion pieces [15-17]. Therefore, we examined the extent of disclosure present in editorials, comments, letters, and perspectives as compared to other article types that expressed an opinion. In addition, authors' COI statements and funding disclosures may not be entirely accurate $[18,19]$. To explore this, we searched for undisclosed industry ties, examining whether such ties were also associated with an article's stance on the use of systematic reviews.

The primary objective of this study was to determine whether industry ties-disclosed or undisclosed-were associated with the conclusions of opinion articles on the use of systematic reviews for health policy decisions. Our secondary objectives were to determine the substance of the arguments that authors were using to support their positions and how disclosure policies vary by journal and by article type and to determine the extent that these articles are being cited in the scientific literature. This study was not intended to be a systematic review, as we did not undertake a comprehensive search with multiple databases, nor did we contact authors for unpublished papers. This is an analysis of a representative sample of available opinion articles.

\section{Methods}

\section{Search strategy}

Opinion pieces are often difficult to locate, are inconsistently indexed, and may have uninformative titles [20,21]. For our systematic investigation, we conducted a preliminary MEDLINE text search ("Systematic reviews for health policy decision making") and consulted a reference librarian to further develop our search strategy. We then conducted four more searches of MEDLINE for all articles published between January 1, 1946, and July 31, 2010, with the following MeSH terms and topics: MetaAnalysis as Topic [Mesh] AND health policy [Mesh]; Review Literature as Topic [Mesh] AND health policy [MAJR]; Review literature as topic [Mesh] AND health policy [Mesh]; and "Meta-analysis" and "problem" as topics.

We included editorials, letters, commentaries, and other articles expressing opinions about the use of systematic reviews for policy. Research articles, including studies, reviews, and case examples, were included if the authors expressed an opinion on the use of systematic 
reviews in policymaking within the body of the article. For included papers, we examined the MEDLINE summary page for associated comments for possible inclusion into our sample. The purpose of this was to understand the debate surrounding a particular publication on the use of systematic reviews in policymaking. In addition, we also included relevant articles from our files.

\section{Selection criteria}

Two researchers (SRF and DHO) screened search result titles to identify articles that appeared in peer-reviewed journals that criticized or supported the use of systematic reviews for making health policy decisions. Titles were excluded if they did not include at least one of the terms: systematic reviews, meta-analysis, evidence-based, Cochrane, medical effectiveness research, drug effectiveness review program, or policy and evidence. Titles were additionally excluded if they appeared to be entirely related to statistical methodology or handling of data or only related to the use of systematic reviews solely for clinical decision-making.

All other titles were included. Each author (SRF and DHO) independently screened each search and compared results. The abstracts and full text of all titles selected by either author were reviewed for inclusion. We also included relevant articles from the author's files that did not appear in the original searches.

Two authors (SRF and DHO) independently screened the abstracts and/or full text of each included title. Discrepancies were resolved by consensus. We included articles that contained significant arguments for or against the use of systematic reviews in policymaking. We considered arguments to be significant if they did not focus solely on a single systematic review, but rather commented on whether systemic reviews did or did not have a role in policymaking. We excluded articles that made no mention or only a brief mention of the use of systematic reviews for policymaking, systematic reviews of a particular topic, tools or instructional articles, articles that were entirely clinically focused, and articles/abstracts that were not available in English or online.

\section{Coding of articles as supportive or critical of the use of systematic reviews to inform policy}

We coded articles as supportive if they promoted wellconducted systematic reviews as a strong method for gathering, evaluating, and disseminating bodies of research. Articles that included suggestions for improvement but still advocated systematic reviews as an important knowledge generation tool for policymakers were also coded as supportive. We coded articles as critical if they argued that systematic reviews did not generate useful or accurate knowledge or argued that the method is currently too limited to be useful.

\section{Coding of individual arguments in each article}

We initially coded each article inductively, abstracting each argument the authors made to support their positions. After analysis, we then thematically grouped similar arguments together for analysis and coded them as "internal reliability" arguments or "external validity" arguments using adapted definitions from previous studies $[14,22]$. Although each article was coded overall as supportive or critical, an individual article could contain both critical and supportive arguments or arguments about internal or external validity.

Two authors (DHO and SRF) coded in duplicate 14\% $(37 / 264)$ of the arguments. We agreed $92 \%$ (34/37) of the time. We resolved disagreements by consensus. One author (SRF) coded the remainder of the articles. We also abstracted illustrative quotes from the articles, qualitatively summarized the arguments, and conducted a content analysis on the abstracted arguments [23].

\section{Internal reliability arguments}

If the authors argued that a well-conducted systematic review was an internally reliable and valid method of collecting and analyzing data, the argument was coded as supportive of internal reliability. If the authors argued that systematic reviews were internally flawed because of issues of selection bias, misclassification, confounding, study heterogeneity, flaws in data pooling and data analysis, and publication bias, the article was coded as critical of internal reliability.

\section{External validity arguments}

If the authors argued that well-conducted systematic reviews were externally valid, useful for highlighting gaps in the literature, or a strong summary source of evidence useful in policy contexts, the argument was coded as a supportive external validity argument. If the authors argued that systematic reviews were not useful for highlighting gaps in the literature, a weak summary source of evidence and/or not useful in policy contexts, and/or not generalizable, the argument was coded as a critical external validity argument.

\section{Coding of disclosures Affiliation of authors}

We coded each included article by the author affiliations stated in the article. If authors claimed more than one affiliation, each type was coded.

\section{Conflicts of interest of authors}

We coded each article for COI by examining disclosures using categories adapted from the International Committee of Medical Journal Editors [24]. We considered study sponsorship/funding separately from COI. If there was an explicit COI statement contained within the article, it was 
considered to have a disclosed COI. We then divided COI statements into three categories: no disclosed COI, industry-related COI, and other, which included all non-industry-related COI such as a school or a government. We coded an article as having an industry-related $\mathrm{COI}$ if at least one author reported explicit financial ties to a for-profit industry. If an article did not have an explicit conflict of interest statement, we coded it as "no information provided."

\section{Funding sources of articles}

We coded all articles by disclosed funding sources. If there was an explicit statement about funding, or that the article had no funding, the paper was considered to include disclosure of its funding source. We coded funding statements into five categories: self-funded or no funding, private non-profit funding, industry funding, government funding, and mixed funding. If an article did not have an explicit funding statement, we coded it as "no information provided."

\section{Industry ties}

For analysis, we collapsed affiliations, COI, and funding sources into one dichotomous variable, "industry tie or no industry tie". Our primary outcome was presence of industry ties by supportive or critical argument.

\section{Extent of disclosure}

We abstracted the date of publication and extent of disclosure statement in each included article. Some journals have only recently required and/or printed COI statements and funding disclosure statements $[17,25,26]$. We identified current $\mathrm{COI}$ and funding disclosure policies for each of the journals in which our study articles appeared. Articles were coded into three categories: no disclosure of either COI or funding source, disclosure of $\mathrm{COI}$ or funding source, or disclosure of $\mathrm{COI}$ and funding source.

\section{Identification of undisclosed COI}

For authors of articles with no disclosed industry ties, we searched MEDLINE for any articles they had published within the 3 years before publication of the included study article. We assessed the disclosures in these articles using criteria set forth by the International Committee of Medical Journal Editors [24]. We classified the disclosures of the authors as: (a) publication of a study sponsored by industry; (b) affiliation with industry at the time of publication, including, but not limited to, employment, board membership, etc.; (c) disclosure of a financial relationship to industry, including patents, stock, research funding, grants, gifts, consultancy, royalties, expert testimony, service on industry speaker's bureau, payments for manuscript preparation or review, travel, lectures, etc., or other relevant financial activities/ relationships [24]. If an industry tie was identified in an article published within the 3 prior years of the study article, we categorized the study article as having an undisclosed industry tie. We then discontinued our search for the remaining publications related to the study article, including publications by co-authors.

We also searched the Integrity in Science (ISS) database that contains over 4,000 scientists with corporate ties [27]. Up until 2009, when the database stopped collecting data, the researchers at ISS routinely scrutinized more than 200 science-based federal advisory committees for undisclosed conflicts of interest and monitored the media and scientific literature for failure to disclose. While the database is not comprehensive, it does provide an additional resource to examine corporate ties of scientists. If an author of a study article was listed as having an industry tie within the last 3 years in the ISS database, we categorized the study article as having an undisclosed industry tie.

\section{Citations of included articles in the academic literature}

We searched the academic search engine "Web of Science" and recorded the number of citations for each article included in our study as of November 2013. We used this number as a proxy measure for the extent that the article was being used as evidence within the academic community.

\section{Analysis}

After articles were selected for inclusion, each article was closely read by two authors (SRF and DHO) and a decision was reached about whether the article was supportive or critical of the use of systematic reviews in policymaking. Discrepancies were resolved by a third author (LAB). Using an author-generated data collection sheet, we coded full citation and article type, whether the article was supportive or critical of the use of systematic reviews to inform policy, individual argument types, affiliations of authors, stated conflicts of interest of all authors, funding source of articles, and extent of disclosure, as described below. Once all data from the article had been extracted, we then searched for undisclosed industry ties and individual journal disclosure policies. Finally, we identified the number of times each article had been cited in the academic literature.

All data were analyzed using descriptive statistics, as the use of inferential statistics was inappropriate due to the non-randomness of the sample.

\section{Results}

We screened a total of 533 article titles including ten from the author's files and seven from comments associated 


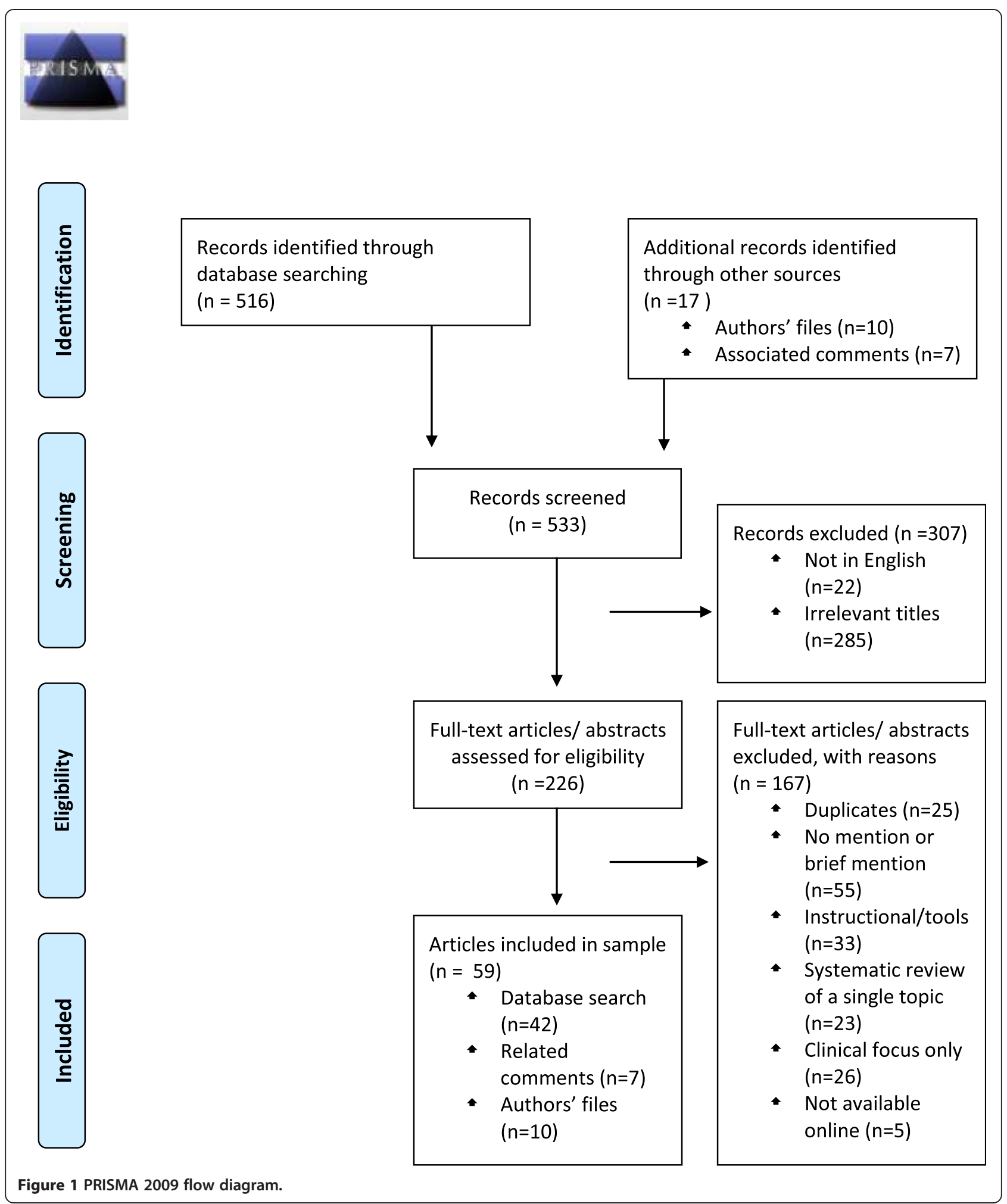

with the articles (see Figure 1). Twenty-two articles were excluded because they were not in English (see Additional file 1). Of the 59 included articles (see Additional file 2), nearly $34 \%$ (20/59) of the included articles were editorials, comments, letters, and perspectives, while 66\% (39/59) of the articles were research, reviews, and case studies. All included articles were published between 1991 and July 2010. We coded 58\% (34/59) articles as supportive of 
using systematic reviews to inform policy and $42 \%(25 / 59)$ as critical.

\section{Disclosure of affiliation, conflict of interest, and funding source}

Table 1 shows the extent of disclosure found in the study articles. Forty-two percent (25/59) of both supportive and critical articles contained no COI or funding source disclosures, whereas $21 \%(7 / 34)$ and $24 \%(6 / 25)$ of the articles, respectively, had both $\mathrm{COI}$ and funding disclosures. Disclosure status appeared to improve over time. The median publication date for articles without disclosures was 2003 for both supportive and critical articles, compared to 2008 for articles with COI and funding disclosures.

Table 2 shows the extent of disclosures found in the study articles by article type. Sixty percent (12/20) of the editorials, comments, letters, or perspectives did not contain either COI statements or funding disclosures, compared to $33 \%$ of the other article types considered.

Table 3 shows disclosed affiliations, COI, and funding sources of the study articles. We found similar rates of disclosed university affiliations among supportive and critical authors. However, more supportive authors were affiliated with government and considerably more critical authors were affiliated with the pharmaceutical, tobacco, or insurance industries, the three industries represented in our sample. The majority of papers did not have explicit COI statements. However, 26\% (9/34) of the supportive authors explicitly stated that they did not have COI, compared to $8 \%(2 / 25)$ of the critical authors. Conversely, $32 \%$ $(8 / 25)$ of the critical authors had an explicitly stated industry-related COI as compared to $3 \%(1 / 34)$ of the supportive authors. Funding statements were almost equally scarce among supportive and critical articles, and no article listed more than one funding source. Of those articles

Table 1 Extent of disclosures made within the articles

\begin{tabular}{lcc}
$\begin{array}{l}\text { Extent of disclosure in study } \\
\text { articles }\end{array}$ & $\begin{array}{c}\text { Supportive } \\
\text { papers } \\
(\boldsymbol{n}=\mathbf{3 4})\end{array}$ & $\begin{array}{c}\text { Critical } \\
\text { papers } \\
(\boldsymbol{n}=\mathbf{2 5})\end{array}$ \\
\hline $\begin{array}{l}\text { No disclosure of either conflicts of } \\
\text { interest or funding source }(\%, n)\end{array}$ & $41(14)$ & $44(11)$ \\
$\quad$ Median date & 2003 & 2006 \\
$\quad$ Date range & $1995-2010$ & $1991-2010$ \\
$\begin{array}{l}\text { Disclosure of conflicts of interest } \\
\text { or funding source }(\%, n)\end{array}$ & $38(13)$ & $32(8)$ \\
$\quad$ Median date & 2005 & 2005 \\
$\quad$ Date range & $2000-2009$ & $1991-2010$ \\
$\begin{array}{l}\text { Disclosure of conflicts of interest } \\
\text { and funding source }(\%, n)\end{array}$ & $21(7)$ & $24(6)$ \\
$\quad$ Median date & & 2008 \\
Date range & $2005-2009$ & $2003-2010$ \\
\hline
\end{tabular}

that disclosed funding sources, more articles critical of systematic reviews were funded by industry.

\section{Industry ties-disclosed and undisclosed}

Table 4 shows industry ties that were disclosed in the included article and industry ties that were found in the 3 -year retrospective search for undisclosed ties. Critical articles were about six times more likely to have a disclosed industry tie than supportive articles; 6\% (2/34) of supportive articles and $40 \%(10 / 25)$ of critical articles disclosed industry ties. While this gap narrowed when we included industry ties found in the retrospective 3-year search, critical articles had an industry tie more than twice as often as did supportive articles (35\%, 12/34 v. 80\%, 20/25).

\section{Journal disclosure policies}

At the time we conducted our study, most journals had current disclosure policies. The 15 articles critical of systematic reviews that did not disclose industry ties were published in 12 distinct journals. Among these journals, 9 of the 12 currently require authors to disclose their conflicts of interest and 6 of the 12 require authors to disclose their funding sources. The 32 supportive study articles that did not disclose industry ties were published in 20 distinct journals. Among these journals, 17 of the 20 currently require authors to disclose their conflict of interest and 13 of the 20 require authors to disclose their funding sources (data not shown in tabular form).

\section{Article citations}

Table 5 shows the number of times that the included articles have been cited within the academic literature by article type and by whether the article was supportive or critical. Interestingly, $48 \%(12 / 25)$ of articles critical of systematic reviews were editorials, comments, letters, and perspectives, while only $24 \%(8 / 34)$ of supportive articles were editorials, comments, letters, and perspectives. Taken together, editorials, comments, letters, and perspectives were cited less often than other article types (median citations 5 v. 19); however, they still received a number of citations within the literature.

\section{Argument analysis Internal reliability arguments}

We abstracted 151 individual arguments from the 34 supportive articles. Of these 151, 37\% (56/151) were arguments in support of the internal reliability of wellconducted systematic reviews. Authors typically argued that the methods of well-conducted systematic reviews reduce bias. Lavis et al. contended that this lack of bias, as well the transparency and comprehensiveness of systematic review methodology, provides policymakers with more complete and valid information than they are likely to encounter in individual studies [28]. 
Table 2 Extent of disclosures in editorials, comments, letters, and perspectives compared to other article types

\begin{tabular}{|c|c|c|c|}
\hline & Supportive & Critical & Total \\
\hline Extent of disclosure in editorials, comments, letters, and perspectives & $(n=8)$ & $(n=12)$ & $(n=20)$ \\
\hline No disclosure of either conflicts of interest or funding source $(\%, n)$ & $50(4)$ & $67(8)$ & $60(12)$ \\
\hline Disclosure of conflicts of interest or funding source $(\%, n)$ & $37(3)$ & $17(2)$ & $25(5)$ \\
\hline Disclosure of conflicts of interest and funding source $(\%, n)$ & $13(1)$ & $17(2)$ & $15(3)$ \\
\hline Extent of disclosures in other article types & $(n=26)$ & $(n=13)$ & $(n=39)$ \\
\hline No disclosure of either conflicts of interest or funding source $(\%, n)$ & $38(10)$ & $23(3)$ & $33(13)$ \\
\hline Disclosure of conflicts of interest or funding source $(\%, n)$ & $38(10)$ & $46(6)$ & $41(16)$ \\
\hline Disclosure of conflicts of interest and funding source $(\%, n)$ & $23(6)$ & $31(4)$ & $26(10)$ \\
\hline
\end{tabular}

We abstracted 113 individual arguments from the 25 critical articles. Of these $113,62 \%(70 / 113)$ were arguments that were critical of the internal reliability of systematic reviews. Typically, authors argued that the research studies used in systematic reviews are too dissimilar to be combined into a summary statement or statistic, included studies are cherry-picked; and that studies are excluded because of investigator bias, not because of inherent problems with the study. These authors argued that systematic reviews magnify publication bias or that they are often dependent on small numbers

\section{Table 3 Disclosed affiliations, conflicts of interest, and funding source by opinion on the use of systematic reviews for policymaking}

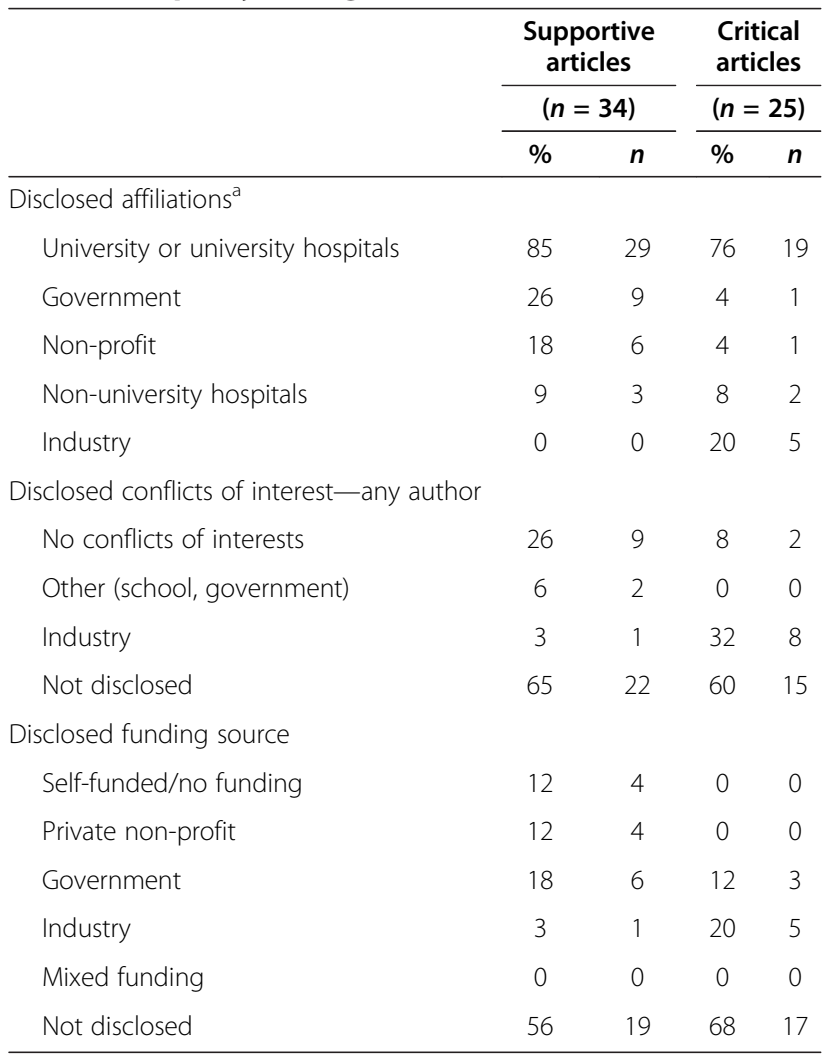

${ }^{\text {a }}$ Totals add to more than 100 as some papers had more than one affiliation. of underpowered and methodologically inadequate trials. Critical authors also contend that the methods used are not transparent, that research questions asked by systematic reviews are too narrowly focused to be of any use, or that meta-analyses may use analyses of information from subgroups collected after randomization, resulting in the possibility that the confounding variables may no longer be distributed at random. In a recent critical article that reviewed four published systematic reviews, the authors note that weaknesses encountered in many meta-analyses often stem not from the method itself, but from the poor design and reporting of the trials that make up the body of evidence available to answer the particular research question. They argued that this is exacerbated when the authors of meta-analyses fail to exclude poor-quality studies or to account for the variability in study quality by performing sensitivity analyses [29]. A commentary in the New England Journal of Medicine questioning the conclusions of several metaanalyses that found that secondhand smoke is harmful to health presented many common criticisms of these studies, including authors' bias and lack of subject matter expertise, subject matter experts' misunderstanding of meta-analytic methods, and such methodological flaws as failure to include relevant co-variables or account for heterogeneity or varying effect sizes in different populations [5].

\section{External validity arguments}

External validity arguments occurred almost twice as often in supportive arguments as did internal validity arguments $(63 \%$ v. $37 \%)$. The authors of these articles generally argued that well-conducted systematic reviews were the highest level of evidence available [30,31] and effectively summarized large bodies of evidence, resulting in strong external validity [32]. Supportive authors also asserted that systematic reviews were useful in identifying gaps in the literature and highlighting research priorities.

Thirty-eight percent (43/113) articles critical of systematic reviews contained external validity arguments; 
Table 4 Industry ties (disclosed and not disclosed) by opinion on the use of systematic reviews for policymaking

\begin{tabular}{|c|c|c|c|c|}
\hline \multirow[t]{3}{*}{ Industry ties } & \multirow{2}{*}{\multicolumn{2}{|c|}{$\begin{array}{c}\begin{array}{c}\text { Supportive } \\
\text { articles }\end{array} \\
(n=34)\end{array}$}} & \multirow{2}{*}{\multicolumn{2}{|c|}{$\begin{array}{r}\text { Critical } \\
\text { articles } \\
(n=25)\end{array}$}} \\
\hline & & & & \\
\hline & $\%$ & $n$ & $\%$ & $n$ \\
\hline Industry ties disclosed in the article & 6 & 2 & 40 & 10 \\
\hline $\begin{array}{l}\text { Articles with industry ties not disclosed } \\
\text { in the paper, but found on a 3-year } \\
\text { retrospective search of previously } \\
\text { disclosed industry ties in other articles }\end{array}$ & 29 & 10 & 40 & 10 \\
\hline $\begin{array}{l}\text { Total articles with industry ties (disclosed } \\
\text { in the paper and those found on a 3-year } \\
\text { retrospective search) }\end{array}$ & 35 & 12 & 80 & 20 \\
\hline
\end{tabular}

however, they generally were extensions of arguments made that were critical of the internal reliability of systematic reviews, arguing that there can be no external validity because of the poor internal validity and reliability. For example, Eysenck [33] argued that the results of a meta-analysis on the toxicity of secondhand smoke by the National Research Council were scientifically meaningless and should not be used in policymaking because of detection bias resulting from unreliable cause of death information on death certificates, authors' reliance on effect size, and exclusion of "evidence relevant to the paradigm of research."

In five critical articles [34-38], and six supportive [30,39-43], authors expressed concerns about generalizability of systematic review results. The critical articles primarily argued that results were too general to be applied with confidence to individuals or typical patient populations and warned that the results might not

Table 5 Citations of editorials, comments, letters, and perspectives in the academic literature as compared to other article types (from the Web of Science by November 2013)

\begin{tabular}{lccc}
\hline & $\begin{array}{c}\text { Supportive } \\
\text { articles }\end{array}$ & $\begin{array}{c}\text { Critical } \\
\text { articles }\end{array}$ & $\begin{array}{c}\text { Total } \\
\text { articles }\end{array}$ \\
\hline $\begin{array}{l}\text { Editorials, comments, letters, and } \\
\text { perspectives }\end{array}$ & $(n=8)$ & $(n=12)$ & $(n=20)$ \\
Total number of citations & 146 & 220 & 366 \\
Average number of citations & 18 & 18 & 18 \\
Median number of citations & 5.5 & 3 & 5 \\
Range of citations & $0-107$ & $0-78$ & $0-107$ \\
Other article types (reviews, & $(n=26)$ & $(n=13)$ & $(n=39)$ \\
research, and case studies) & 1109 & 604 & 1713 \\
Total number of citations & 43 & 50 & 44 \\
Average number of citations & 19 & 21 & 19 \\
Median number of citations & $0-490$ & $5-220$ & $0-490$ \\
\hline Range of citations & & &
\end{tabular}

capture complexities of disease and treatment or biological, environmental, and contextual variability. One [37] raised questions about the utility to physicians of summary statistics; another [36] described the process of pooling heterogeneous patient data as "the risks run in pooling data from different studies to determine care guidelines are enormous". Two critical articles discussed social context $[34,38]$. Neumann et al. criticized the Drug Effectiveness Review Project, which produces systematic reviews of drug-drug comparisons that are used by some US states to develop Medicaid preferred drug lists for not adequately considering costs and a "full societal perspective" [34]. Most of the critical articles concluded that intractable flaws in systematic review methods greatly decreased their external validity and suggested that policymakers use caution and take other sources of information into account when making health policy decisions. While most of the critical articles did not raise issues of health equity, Ahmad et al. [38] expressed concerns about the use by public health policymakers in low-income countries of systematic reviews of studies that are conducted primarily in high-income countries. The authors were concerned that systematic reviews on HIV prevention and tobacco cessation lacked cultural and socioeconomic context, rendering the findings potentially less useful for developing policies and practice guidelines in low-income countries. The authors identified steps that systematic review authors could take to increase the strength of review-based recommendations for developing countries.

Six otherwise supportive articles also expressed concerns about generalizability. One [30] advised policymakers to consider contextual factors and study populations when applying systematic review results. Five articles [39-43] argued that while systematic reviews provided the best available evidence for development of health policies and practice guidelines, they did not adequately address issues of health equity or account for differences in socioeconomic status, racial/ethnic diversity, and other social health determinants. All of these articles made recommendations to authors and policymakers for tools and approaches, many of them interdisciplinary, that they can use to enhance the utility of systematic reviews for the development of equitable health policy. One article advocating for evidence-based health promotion recommends that authors increase applicability of their reviews by taking into consideration the salience of the topic and outcome measures and the practical and cost implications of the interventions that are being considered [43]. Other authors stress the importance of providing credible evidence that is convincing within the health sector and also among non-health collaborators [40].

Articles without industry ties were more likely to accept systematic review methods as internally reliable 
and valid, focusing on the relevance of systematic reviews for policymaking, making arguments to support why and how policymakers should consider the results of systematic reviews in their policy decision-making. Articles that were critical of systematic reviews, but did not have industry ties, were more likely to make highly nuanced arguments expressing concern about the generalizability of systematic review results to diverse populations.

\section{Discussion}

Our findings suggest that articles critical of the use of systematic reviews for policymaking are more likely to have industry ties than supportive articles. One possible explanation is that authors of well-conducted systematic reviews, such as those done by The Cochrane Collaboration, examine all of the data available about a topic, including unpublished data when possible, and select for inclusion studies that meet rigorous criteria [11]. Systematic reviews that are conducted according to strict predefined protocols leave industry with less ability to direct or criticize the review findings. By considering all of the available data, the summary effect estimate from a welldone systematic review should represent the current state of the science on the topic in question. Studies that are funded by industry are considered as part of the evidence, but usually not as the only evidence. This may leave industry with less control over the discourse, introducing variability and the possibility that their product, process, or service may not be the most efficacious. For example, unpublished data are more likely to show that a study drug is ineffective than data that are published [44-47]. Systematic reviews attempt to capture and include this information, thus leading to results that may ultimately conflict with the results of industry-sponsored randomized controlled trials.

Our findings also suggest that current journal disclosure requirements for articles are frequently inadequate, especially for editorials, comments, letters, and perspectives. These types of articles lacked any type of disclosure three times as often as the other article types. Editorials, comments, letters, and perspectives play an active role in the academic discourse, as evidenced by the number of times they have been cited in the literature. Together, the included articles have been cited 2,079 times in the literature with editorials, comments, letters, and perspectives cited 366 times. However, it should be noted that citations can either be favorable or unfavorable and that the total number of citations does not necessarily equate with the influence of the article.

Overall, 42\% (25/59) of all the included articles, including some that were recently published, did not have any disclosures, leaving readers with no information on the author's affiliations, funding sources, and COI. Others only had partial disclosures. Our detailed 3-year retrospective search found that 43\% (20/47) of articles that had no disclosed industry ties had at least one author with an undisclosed industry tie from the previous 3 years. Having this information readily available is important when readers evaluate the strength of an argument and possible bias. By not requiring the information, or not printing it, journals may leave readers inadequately prepared to accurately judge an article's accuracy or usefulness.

Our results are consistent with previous studies that showed a positive relationship between industry ties and favorable conclusions in research articles, even when the results of the study do not support the conclusions drawn $[13,14,45,48]$. Our research suggests that opinion pieces may be subject to similar biases as other article types and provides evidence that funding sources and COI for all article types should be made transparent.

Our research has several limitations. Because of the inherent difficulties of locating opinion articles, we acknowledge that it is likely that our list of included papers was not comprehensive. Rather, our aim was to perform a systematic search of the topic for a representative sample of articles. As our sample was not a random sample, we elected not to do inferential statistics with the results so that there would be no suggestion of false precision. Because of variable disclosure requirements of journals, we likely have under-estimated the number of industry ties in our sample. For example, one critical article, written during the debates over secondhand smoke [33], did not list any disclosures, nor did we find any industry ties during our 3-year retrospective search. This paper was catalogued in our study as not having any industry ties. However, a British newspaper [49] wrote that this particular researcher had received about 800,000 pounds from the tobacco industry. Finally, researchers who do not directly receive payments from industry may work at institutions in which industry funds infrastructure. We did not capture these relationships.

\section{Conclusions}

Our findings are important because they demonstrate that industry ties may play a role in opinions expressed in the scientific literature. Moreover, opinion articles are often subsequently cited in the debate as evidence of the controversy over the use of systematic reviews in policymaking. Our results suggest the need for more consistent and complete disclosure for all article types, including articles that may not go through the traditional peer review process, such as editorials, commentaries, letters, and perspectives.

It is important to consider the industry ties of the authors when evaluating arguments regarding the use of systematic reviews by health policymakers and other decision makers. The conduct of systematic reviews is far 
from a perfect science, and there are substantial and nuanced criticisms of the generalizability of the results. While these arguments may be valid and should not be ignored, it is essential that we consider how knowledge generated by scientists can be critically summarized and subsequently translated for use in policymaking and population health decision-making. Well-conducted systematic reviews provide a rigorous and transparent method for knowledge dissemination and should be improved, not discarded.

\section{Additional files}

Additional file 1: Study articles excluded for being in a language other than English. Additional file 1 lists all studies from the original sample that were excluded because they were not in English.

Additional file 2: Included study articles. Additional file 2 lists all studies included in the sample, including studies obtained from database searching, related commentary, and author's files.

\section{Competing interests}

Susan Forsyth, Donna Odierna, and Lisa Bero are affiliated with The Cochrane Collaboration. The authors have no other competing interests to declare.

\section{Authors' contributions}

SRF assisted with the project development, collected and analyzed the data and prepared drafts of the manuscript. DHO collaborated on the project development, developed the initial coding scheme, collected the data, wrote sections of the manuscript, and reviewed the drafts. DK collected the data and reviewed the drafts. LAB collaborated on the project development, contributed to the analysis of data, and reviewed the drafts. All authors read and approved the final manuscript.

\section{Acknowledgements}

We would like to thank Mark Gibson for the assistance with development of the study protocol. We are also grateful to the research staff at the UCSF Library, the UCSF Tobacco Center, and the Drug Industry Document Archive for the assistance with search strategies.

\section{Funding}

This project was funded by the Flight Attendant Medical Research Institute (FAMRI), Miami, FL, USA. Susan Forsyth is funded by a dissertation award from the Tobacco-Related Disease Research Program (TRDRP; grant \#22DT-0003).

\section{Author details}

'Department of Social and Behavioral Sciences, School of Nursing, University of California, San Francisco, CA, USA. ²Department of Clinical Pharmacy, University of California, San Francisco, CA, USA. ${ }^{3}$ nstitute for Health Policy Studies, University of California, San Francisco, CA, USA. ${ }^{4}$ Charles Perkins Centre, University of Sydney, Sydney, Australia.

Received: 6 June 2014 Accepted: 14 October 2014 Published: 18 November 2014

\section{References}

1. Bero LA, Jadad AR: How consumers and policymakers can use systematic reviews for decision making. Ann Intern Med 1997, 127:37-42.

2. Sweet M, Moynihan R, Fund MM: Improving Population Health: The Uses of Systematic Reviews. New York: Milbank Memorial Fund; 2007.

3. Fox DM: The governance of standard-setting to improve health. Prev Chronic Dis 2010, 7:A123.

4. Fox DM: Systematic reviews and health policy: the influence of a project on perinatal care since 1988. Milbank Q 2011, 89:425-449.

5. Bailar JC III: Passive smoking, coronary heart disease, and meta-analysis. N Engl J Med 1999, 340:958-959.
6. Chalmers I, Hedges LV, Cooper H: A brief history of research synthesis. Eval Health Prof 2002, 25:12-37.

7. Meerpohl JJ, Herrle F, Antes G, von Elm E: Scientific value of systematic reviews: survey of editors of core clinical journals. PLoS One 2012, 7:e35732.

8. Greenhalgh T, Potts HW, Wong G, Bark P, Swinglehurst D: Tensions and paradoxes in electronic patient record research: a systematic literature review using the meta-narrative method. Milbank Q 2009, 87:729-788.

9. Thomas J, Harden A: Methods for the thematic synthesis of qualitative research in systematic reviews. BMC Med Res Methodol 2008, 8:45.

10. Barnett-Page $E$, Thomas J: Methods for the synthesis of qualitative research: a critical review. BMC Med Res Methodol 2009, 9:59.

11. Higgins JPT, Green S (Eds): Cochrane Handbook for Systematic Reviews of Interventions Version 5.1. O [updated March 2011]. The Cochrane Collaboration; 2011 [www.cochrane-handbook.org]

12. Lundh A, Sismondo S, Lexchin J, Busuioc Octavian A, Bero L: Industry sponsorship and research outcome. Cochrane Database Syst Rev 2012. Issue 12. Art. No.: MR000033. doi:10.1002/14651858.MR000033.pub2. 2012.

13. Bartels RH, Delye H, Boogaarts J: Financial disclosures of authors involved in spine research: an underestimated source of bias. Eur Spine J 2012, 21:1229-1233

14. Yank V, Rennie D, Bero LA: Financial ties and concordance between results and conclusions in meta-analyses: retrospective cohort study. BMJ 2007, 335:1202-1205.

15. Forbes TL: Author disclosure of conflict of interest in vascular surgery journals. J Vasc Surg 2011, 54:55S-58S.

16. Kesselheim AS, Lee JL, Avorn J, Servi A, Shrank WH, Choudhry NK: Conflict of interest in oncology publications. Cancer 2012, 118:188-195.

17. Blum JA, Freeman K, Dart RC, Cooper RJ: Requirements and definitions in conflict of interest policies of medical journals. JAMA 2009, 302:2230-2234.

18. Okike K, Kocher MS, Wei EX, Mehlman CT, Bhandari M: Accuracy of conflictof-interest disclosures reported by physicians. N Engl J Med 2009, 361:1466-1474.

19. Bero $L A$, Glantz $\mathrm{S}$, Hong $M-K$ : The limits of competing interest disclosures. Tob Control 2005, 14:118-126.

20. Harden A, Garcia J, Oliver S, Rees R, Shepherd J, Brunton G, Oakley A: Applying systematic review methods to studies of people's views: an example from public health research. J Epidemiol Community Health 2004, 58:794-800.

21. Woodman J, Harden A, Thomas J, Brunton J, Kavanagh J, Stansfield C: Searching for systematic reviews of the effects of social and environmental interventions: a case study of children and obesity. J Med Libr Assoc 2010, 98:140.

22. Schotland MS, Bero LA: Evaluating public commentary and scientific evidence submitted in the development of a risk assessment. Risk Anal 2002, 22:131-140

23. Weber RP: Basic Content Analysis. Newbury Park: Sage; 1990

24. International Committee of Medical Journal Editors: International Committee of Medical Journal Editors (ICMJE): uniform requirements for manuscripts submitted to biomedical journals: writing and editing for biomedical publication. Haematologica 2004, 89:264.

25. Ancker JS, Flanagin A: A comparison of conflict of interest policies at peer-reviewed journals in different scientific disciplines. Sci Eng Ethics 2007, 13:147-157.

26. Meerpohl JJ, Wolff RF, Niemeyer CM, Antes G, von Elm E: Editorial policies of pediatric journals: survey of instructions for authors. Arch Pediatr Adolesc Med 2010, 164:268-272.

27. Integrity in Science. [http://www.cspinet.org/integrity/index.html]

28. Lavis JN, Posada FB, Haines A, Osei E: Use of research to inform public policymaking. Lancet 2004, 364:1615-1621.

29. Coyne JC, Thombs BD, Hagedoorn M: Ain't necessarily so: review and critique of recent meta-analyses of behavioral medicine interventions in health psychology. Health Psychol 2010, 29:107.

30. Chan KS, Morton SC, Shekelle PG: Systematic reviews for evidence-based management: how to find them and what to do with them. Am J Manag Care 2004, 10:806-812.

31. Coffman JM, HONG MK, Aubry WM, Luft HS, Yelin E. Translating medica effectiveness research into policy: lessons from the California Health Benefits Review Program. Milbank Q 2009, 87:863-902.

32. Brownson RC, Fielding JE, Maylahn CM: Evidence-based public health: a fundamental concept for public health practice. Annu Rev Public Health 2009, 30:175-201. 
33. Eysenck H: Meta-analysis or best-evidence synthesis? J Eval Clin Pract 1995, 1:29-36.

34. Neumann PJ, Drummond MF, Jönsson B, Luce BR, Schwartz JS, Siebert U, Sullivan SD: Are key principles for improved health technology assessment supported and used by health technology assessment organizations? Int Technol Assess Health Care 2010, 26:71-78.

35. Laupacis A, Straus S: Systematic reviews: time to address clinical and policy relevance as well as methodological rigor. Ann Intern Med 2007, 147:273-274.

36. Marini JJ: Meta-analysis: convenient assumptions and inconvenient truth. Crit Care Med 2008, 36:328-329.

37. Goodman SN: Have you ever meta-analysis you didn't like? Ann Intern Med 1991, 114:244-246.

38. Ahmad N, Boutron I, Dechartres A, Durieux P, Ravaud P: Applicability and generalisability of the results of systematic reviews to public health practice and policy: a systematic review. Trials 2010, 11:20.

39. Tugwell P, Robinson V, Grimshaw J, Santesso N: Systematic reviews and knowledge translation. Bull World Health Organ 2006, 84:643-651.

40. Rychetnik L, Wise M: Advocating evidence-based health promotion: reflections and a way forward. Health Promot Int 2004, 19:247-257.

41. Petticrew M, Tugwell P, Welch V, Ueffing E, Kristjansson E, Armstrong $R$ Doyle J, Waters E: Better evidence about wicked issues in tackling health inequities. J Public Health 2009, 31:453-456.

42. Odierna DH, Bero LA: Systematic reviews reveal unrepresentative evidence for the development of drug formularies for poor and nonwhite populations. J Clin Epidemiol 2009, 62:1268-1278.

43. Gruen RL, Morris PS, McDonald EL, Bailie RS: Making systematic reviews more useful for policy-makers. Bull World Health Organ 2005, 83:480.

44. Rising K, Bacchetti P, Bero L: Reporting bias in drug trials submitted to the Food and Drug Administration: review of publication and presentation. PLoS Med 2008, 5:e217.

45. Hart B, Lundh $A$, Bero $L$ : Effect of reporting bias on meta-analyses of drug trials: reanalysis of meta-analyses. BMJ 2012, 344:d7202.

46. Gøtzsche PC: Why we need easy access to all data from all clinical trials and how to accomplish it. Trials 2011, 12:249.

47. Doshi P, Jefferson T, Del Mar C: The imperative to share clinical study reports: recommendations from the Tamiflu experience. PLoS Med 2012, 9:e1001201.

48. Boutron I, Dutton S, Ravaud P, Altman DG: Reporting and interpretation of randomized controlled trials with statistically nonsignificant results for primary outcomes. JAMA 2010, 303:2058-2064.

49. Pringle P: Eysenck took pounds 800,000 tobacco funds. The Independent. London: Independent Print Limited; 1996.

doi:10.1186/2046-4053-3-122

Cite this article as: Forsyth et al:: Conflicts of interest and critiques of the use of systematic reviews in policymaking: an analysis of opinion articles. Systematic Reviews 2014 3:122.

\section{Submit your next manuscript to BioMed Central and take full advantage of:}

- Convenient online submission

- Thorough peer review

- No space constraints or color figure charges

- Immediate publication on acceptance

- Inclusion in PubMed, CAS, Scopus and Google Scholar

- Research which is freely available for redistribution 